\title{
Erratum to: Clinical Applications of Naturally Derived Biopolymer-Based Scaffolds for Regenerative Medicine
}

\author{
Whitney L. Stoppel, ${ }^{1}$ Chiara E. Ghezzi, ${ }^{1}$ Stephanie L. McNamara,,${ }^{1,2,3}$ Lauren D. Black III, ${ }^{1,2}$ \\ and DAVID L. KAPLAN ${ }^{1}$
}

${ }^{1}$ Department of Biomedical Engineering, Tufts University, Medford, MA 02155, USA; ${ }^{2}$ Cellular, Molecular and Developmental Biology Program, Sackler School of Graduate Biomedical Sciences, Tufts University School of Medicine, Boston, MA 02111, USA; and ${ }^{3}$ The Harvard/MIT MD-PhD Program, Harvard Medical School, Boston, MA 02115, USA

Erratum to: Annals of Biomedical Engineering

Vol. 43, No. 3, March 2015(2014)

pp. $657-680$

DOI: $10.1007 / \mathrm{s} 10439-014-1206-2$

Due to an error in the production process, Lauren D. Black's name was mistagged in the electronic version of the article it has been properly tagged here.

Address correspondence to David L. Kaplan, Department of Biomedical Engineering, Tufts University, Medford, MA 02155, USA. Electronic mail: david.kaplan@tufts.edu

The online version of the original article can be found under doi: 10.1007/s10439-014-1206-2. 